\title{
Cellular Differentiation Grade Code
}

National Cancer Institute

\section{Source}

National Cancer Institute. Cellular Differentiation Grade Code. NCI Thesaurus. Code C93526.

A coded value specifying the degree of cellular differentiation in a sample. 